\title{
CHRNA3 Variant for Lung Cancer Is Associated with Chronic Obstructive Pulmonary Disease in Korea
}

\author{
Woo Jin Kim ${ }^{\mathrm{a}}$ Yeon-Mok Oh ${ }^{\mathrm{b}}$ Tae-Hyung Kim ${ }^{\mathrm{g}}$ Ji-Hyun Lee ${ }^{\mathrm{h}}$ Eun-Kyung Kim ${ }^{\mathrm{h}}$ \\ Jin Hwa Lee ${ }^{c}$ Sang-Min Lee ${ }^{d}$ Tae Rim Shin ${ }^{e}$ Ho ll Yoon ${ }^{i}$ Seong-Yong Lim ${ }^{f}$ Sang Do Lee ${ }^{b}$ \\ ${ }^{a}$ Department of Internal Medicine, Kangwon National University, Chuncheon, ${ }^{b}$ Department of Pulmonary and \\ Critical Care Medicine and Clinical Research Center for Chronic Obstructive Airway Diseases, Asan Medical Center, \\ University of Ulsan College of Medicine, 'Department of Internal Medicine, Ewha Womans University Mokdong \\ Hospital, College of Medicine, Ewha Womans University, dDivision of Pulmonary and Critical Care Medicine, \\ Department of Internal Medicine, Clinical Research Institute, Seoul National University Hospital, Lung Institute, \\ Medical Research Center, Seoul National University College of Medicine, ${ }^{e}$ Department of Internal Medicine, \\ Kangnam Sacred Heart Hospital, Hallym University College of Medicine, and f Division of Pulmonary and Critical \\ Care Medicine, Department of Medicine, Kangbuk Samsung Hospital, Sungkyunkwan University School of \\ Medicine, Seoul, ${ }^{9}$ Division of Pulmonology, Department of Internal Medicine, Hanyang University Guri Hospital, \\ Hanyang University College of Medicine, Guri, h Division of Pulmonary and Critical Care Medicine, Department \\ of Internal Medicine, CHA Bundang Medical Center, CHA University School of Medicine, and 'Respiratory Center, \\ Department of Internal Medicine, Seoul National University Bundang Hospital, Seoul National University College of \\ Medicine, Seongnam, South Korea
}

\section{Key Words}

CHRNA3 - Chronic obstructive pulmonary disease - Genetic association

\footnotetext{
Abstract

Background: Genome-wide association studies have identified CHRNA3 as a lung cancer and chronic obstructive pulmonary disease (COPD) candidate gene in non-Hispanic Caucasian cohorts. However, there are differences in minor allele frequencies among ethnic groups, and limited data exists for Asian populations. Objectives: The aim of this casecontrol study was to determine whether there is an association between COPD and genetic variation in CHRNA3 in the Korean population. In addition, we investigated the association of CHRNA3 with intermediate disease phenotypes including emphysema and lung function in COPD subjects. Methods: Two single-nucleotide polymorphisms (SNPs) in
}

CHRNA3 (rs660652 and rs12910984) were genotyped in 219 COPD subjects registered in the Korean Obstructive Lung Disease cohort study and in 305 control subjects. Volumetric computed tomography was performed in all COPD subjects. Emphysema severity was measured quantitatively by determining the volume fraction of the lung below -950 Hounsfield units. Logistic regression analysis for case-control analysis and linear regression modeling for quantitative analysis were performed using SAS. Results: This case-control analysis of 219 COPD patients and 305 control participants identified a significant association between an SNP of CHRNA3 ( $r$ 12910984) and COPD ( $p=0.049)$. Analysis in COPD subjects revealed that genetic variations were not associated with $\mathrm{FEV}_{1}$. There was no association between SNPs and emphysema severity. However, both SNPs were significantly associated with DLCO. Conclusion: Genetic variations in CHRNA3 are associated with COPD in the Korean population.

Copyright @ 2012 S. Karger AG, Basel

Sang Do Lee, Department of Pulmonary and Critical Care Medicine and Clinical Research Center for Chronic Obstructive Airway Diseases Asan Medical Center, University of Ulsan College of Medicine 388-1 Pungnap-dong, Songpa-gu, Seoul 138-736 (South Korea) E-Mail sdlee@amc.seoul.kr 


\section{Introduction}

Chronic obstructive pulmonary disease (COPD) is characterized by airflow limitation that is not fully reversible [1] and has a high worldwide disease prevalence [2]. Although cigarette smoking is a major risk factor, the pathophysiology of COPD is not fully understood. Recently, several studies suggested that exposure to other environmental factors, including biomass smoke [3], may also present important risk factors.

Genetic factors of COPD are also suggested because this disease develops in a subgroup of the population that has environmental exposure [4]. Recently, genome-wide association studies identified significant associations between COPD and novel genes that may be related to the pathophysiology of the disease [5]. Interestingly, the CHRNA3/5 gene region on $15 \mathrm{q} 24 / 25$, which was repeatedly reported to be associated with lung cancer in genome-wide association studies [6,7], is also associated with COPD $[8,9]$. This region also contains IREB2, which has also been shown to be associated with COPD on the basis of results of a gene expression analysis of lung tissues of COPD patients and a genetic association study [10]. In addition, this region is also associated with emphysema [11]. These common genetic susceptibility results for COPD and lung cancer indicate possible common pathogenesis or common risk factors, such as smoking.

Few reports on the genetic associations of COPD exist in Asia. A previous report identified a genetic association between CHRNA and lung cancer in the Chinese population [12], but no reports on COPD genetic associations have been published in an Asian population. Therefore, we investigated whether an association exists between COPD and chromosome 15q25 CHRNA3 in the Korean population. We also investigated the association between CHRNA3 and intermediate disease phenotypes, including emphysema and lung function, in COPD subjects.

\section{Methods}

Study Design and Population

Individuals with COPD were recruited from the Korean Obstructive Lung Disease (KOLD) cohort, a longitudinal prospective study of COPD beginning in June 2005 [13]. Complete computed tomography (CT) scanning data, blood tests, and other clinical information were obtained from all patients. Spirometry was performed using a Vmax22 (SensorMedics, Yorba Linda, Calif., USA) or a PFDX (MedGraphics, St. Paul, Minn., USA). Diffusing capacity for carbon monoxide (DLCO) was measured by the single-breath method using a Vmax229D (SensorMedics) or a Masterlab Body (JaegerAB, Würtburg, Germany). All pulmonary function tests were performed as recommended by the American Thoracic Society [14]. All COPD subjects included in the study had post-bronchodilator $\mathrm{FEV}_{1} / \mathrm{FVC}$ values $<0.7$ and had $>10$ pack-years of smoking history. Control subjects consisted of 305 smokers or ex-smokers with normal lung function selected from the Korean Genome Epidemiology Study (KoGES) [15]. Institutional Review Board approval at all sites and informed consent from all patients were obtained.

\section{CT Scanning}

Volumetric CT scans were performed on all patients at full inspiration and expiration. Using in-house software, images of the whole lung were extracted automatically and calculated. Emphysema severity was measured quantitatively by determining the volume fraction of the lung below -950 Hounsfield units.

\section{Genotyping}

Two tagging single-nucleotide polymorphisms (SNPs) were chosen using the tagger program in Haploview [16]. We used pairwise linkage disequilibrium tagging with a minimum minor allele frequency of 0.10 and an $r^{2}$ threshold of 0.8 based on phase 2 genotype data in the Asian population of the HapMap Project (fig. 1). Two SNPs (rs660652 and rs12910984) out of 13 SNPs in the CHRNA3 gene were selected as tagging SNPs. Genomic DNA was prepared from blood samples from all patients and SNPs were genotyped by the TaqMan method using an ABI Prism 7300 (Applied Biosystems, Foster City, Calif., USA) system and predesigned SNP genotyping assays according to the manufacturer's instructions.

\section{Statistical Analysis}

Hardy-Weinberg equilibrium was assessed using the goodness-of-fit test. Baseline characteristics were analyzed using a t test for quantitative traits and a $\chi^{2}$ test for binary traits. Logistic regression was used to estimate the association with COPD adjusting for age, sex, and smoking amount. Associations between the quantitative phenotypes and SNP genotypes were tested using linear regression models adjusted for age, sex, height, and pack-years of cigarette smoking using SAS 9.1 (SAS Institute, Cary, N.C., USA).

\section{Results}

\section{Demographic Characteristics}

We analyzed 219 subjects with COPD (mean age 66.5 years) registered in the KOLD study and 305 control subjects (mean age 60.5 years). The mean $\mathrm{FEV}_{1}$ of the COPD subjects and the control subjects were 1.46 and 2.76 liters, respectively (table 1). The age and pack-years of cigarette smoking were higher in the study group than in the control group. We adjusted age and smoking intensity in our analysis for associations.

\section{Association between COPD Susceptibility and SNPs}

Two SNPs (rs660652 and rs12910984) were chosen for genotyping. They were in Hardy-Weinberg equilibrium. A case-control analysis adjusting for age, sex, and pack- 
Fig. 1. Linkage disequilibrium structure of SNPs in the CHRNA3 region based on $\mathrm{r}^{2}$ in phase 2 genotype data in the Asian population of the HapMap Project.

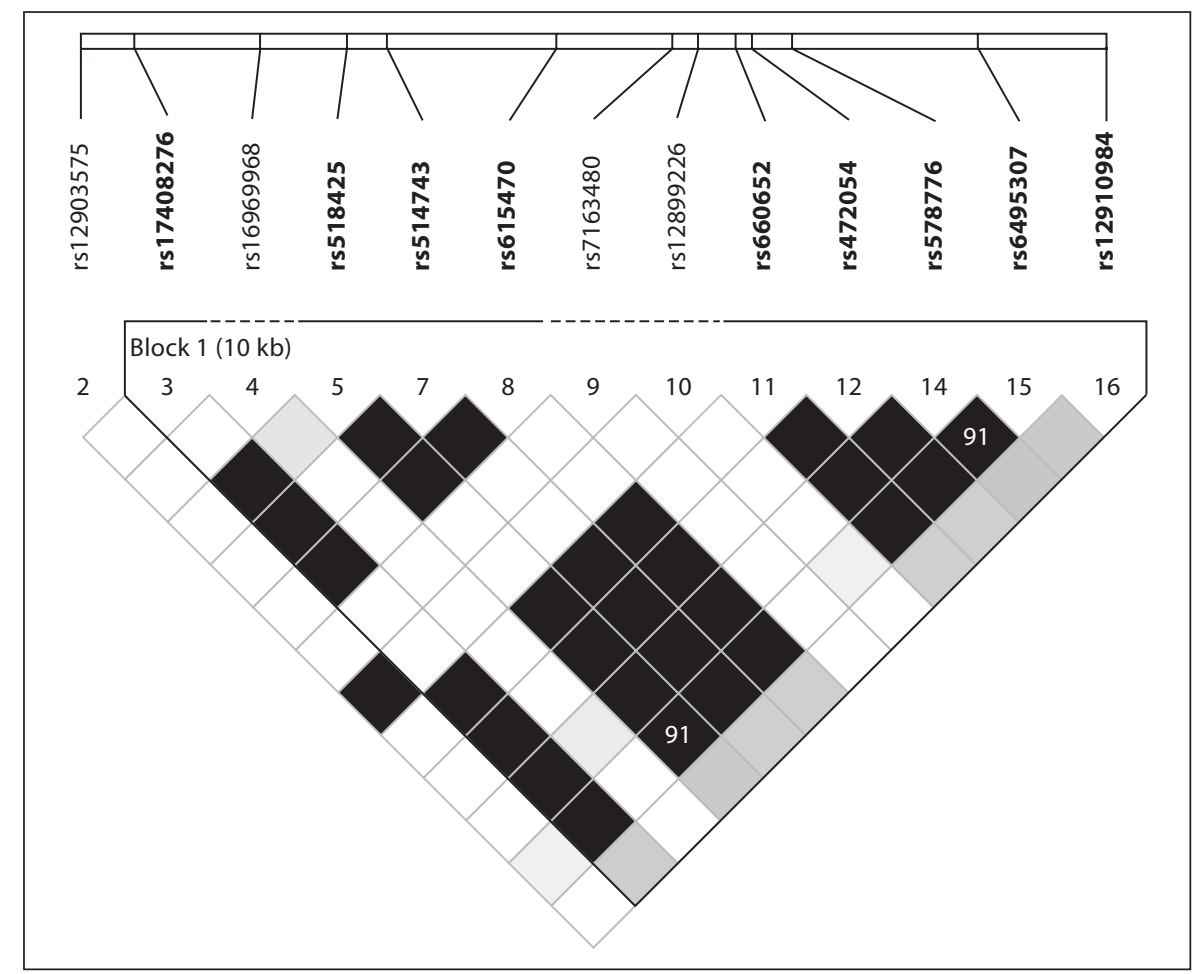

Table 1. Demographic characteristics of analyzed COPD subjects from the KOLD cohort and control subjects from the KoGES

\begin{tabular}{llll}
\hline & COPD & Control & p value \\
\hline Number & 219 & 305 & \\
Males, n (\%) & $210(96)$ & $258(85)$ & $<0.01$ \\
Age, years & $66.2 \pm 7.3$ & $60.5 \pm 6.7$ & $<0.01$ \\
Smoking, pack-years & $47.7 \pm 27.1$ & $33.7 \pm 20.2$ & $<0.01$ \\
FEV $_{1}$, liters & $1.46 \pm 0.5$ & $2.76 \pm 0.3$ & $<0.01$ \\
FEV $_{1}, \%$ of predicted & $48.0 \pm 15.6$ & $113.5 \pm 15.5$ & $<0.01$ \\
DLCO $_{\text {DLCO/VA }}$ & $15.3 \pm 6.08$ & - & \\
Emphysema severity & $2.99 \pm 1.06$ & - & \\
\hline
\end{tabular}

Data represent the means $( \pm S D)$ unless otherwise noted.

years of smoking showed a significant association between rs12910984 and COPD ( $\mathrm{p}=0.049$; table 2), but no such association was identified for rs660652.

\section{Association with Lung Function in COPD Subjects}

Linear regression analysis of COPD subjects adjusting for age, sex, pack-years of smoking, and height revealed that rs660652 was not associated with pre- or postbron- chodilator $\mathrm{FEV}_{1}(\mathrm{p}=0.10$ and $\mathrm{p}=0.34$, respectively). Rs12910984 was also not associated with pre- or postbronchodilator $\mathrm{FEV}_{1}(\mathrm{p}=0.25$ and $\mathrm{p}=0.48$, respectively). DLCO data was available in 195 COPD subjects. Both SNPs were significantly associated with DLCO and DLCO/ VA (table 3). The mean DLCO was lower in the risk allele of rs12910984 for COPD (fig. 2).

\section{Association with Emphysema and Smoking Amount in COPD Subjects}

Emphysema data was available in 197 COPD subjects. The mean emphysema index was $24 \%$ in COPD patients (table 1). There was no association between SNPs and emphysema severity after adjustments for age, sex, height, and smoking amount ( $\mathrm{p}=0.78$ and 0.30 , respectively). There was also no association between SNPs and smoking amount after separate adjustments for age and sex $(\mathrm{p}=0.42$ and $\mathrm{p}=0.72$, respectively).

\section{Discussion}

The association between CHRNA3 polymorphisms and the development of COPD in Asian cohorts has not been analyzed. In this case-control study, we investigated 
Table 2. Association analyses between SNPs in the CHRNA3 gene and COPD

\begin{tabular}{llllll}
\hline & & $\begin{array}{l}\text { COPD } \\
(\mathrm{n}=219)\end{array}$ & $\begin{array}{l}\text { Control } \\
(\mathrm{n}=305)\end{array}$ & Odds ratio & p value \\
\hline rs660652 & GG & 157 & 224 & 1.0 (reference) & \\
& GA & 58 & 71 & $1.23(0.79-1.93)$ & 0.37 \\
& AA & 4 & 10 & $0.77(0.20-2.93)$ & 0.70 \\
\cline { 2 - 5 } rs12910984 & MAF & 0.151 & 0.149 & & 0.60 (trend) \\
& AA & 63 & 67 & $0.67(0.42-1.07)$ & 0.10 \\
& AG & 110 & 160 & $0.50(0.28-0.87)$ & 0.02 \\
& GG & 46 & 78 & & 0.049 (trend) \\
\cline { 2 - 4 } & MAF & 0.461 & 0.518 & & \\
\hline
\end{tabular}

Covariates in the regression models included age, sex, and pack-years of smoking.

MAF $=$ Minor allele frequency.

Table 3. Genetic association analyses of the lung function and emphysema using linear regression in KOLD subjects

\begin{tabular}{|c|c|c|c|c|c|c|c|c|c|c|}
\hline & \multicolumn{2}{|l|}{ Pre-FEV 1} & \multicolumn{2}{|c|}{ Post-FEV 1} & \multicolumn{2}{|l|}{ DLCO } & \multicolumn{2}{|c|}{ DLCO/VA } & \multicolumn{2}{|c|}{ Emphysema } \\
\hline & estimate & $\mathrm{p}$ & estimate & $\mathrm{p}$ & estimate & $\mathrm{p}$ & estimate & $\mathrm{p}$ & estimate & $\mathrm{p}$ \\
\hline rs12910984 & -0.06 & 0.25 & -0.04 & 0.48 & 1.26 & 0.03 & 0.29 & 0.006 & 2.96 & 0.30 \\
\hline
\end{tabular}

whether an association exists between COPD and chromosome $15 \mathrm{q} 25$ CHRNA3 variants in the Korean population. We also investigated the association of CHRNA3 with intermediate disease phenotypes, including emphysema and lung function in COPD subjects. We found that rs12910984, an SNP of CHRNA3, is associated with COPD, suggesting that a genetic association between CHRNA3 and COPD could be replicated in an Asian COPD cohort at the gene level. We also found that both SNPs were associated with DLCO in the COPD cohort.

In previous reports, SNPs in chromosome 15q25 and in the region that includes rs1051730 in CHRNA3 and rs8034191 in LOC123688 were found to be associated with lung cancer and COPD in Caucasian populations [6, 7]. The most significant SNP in studies in Caucasian populations was rs1051730. However, the minor allele frequency of this SNP in Asians is very low. While one study reports a significant association between lung cancer and this SNP in the Japanese population [17], replication at the SNP level is difficult. In the present study, we used tagging SNPs in an Asian database using HapMap. In a previous lung cancer association study in China, risk

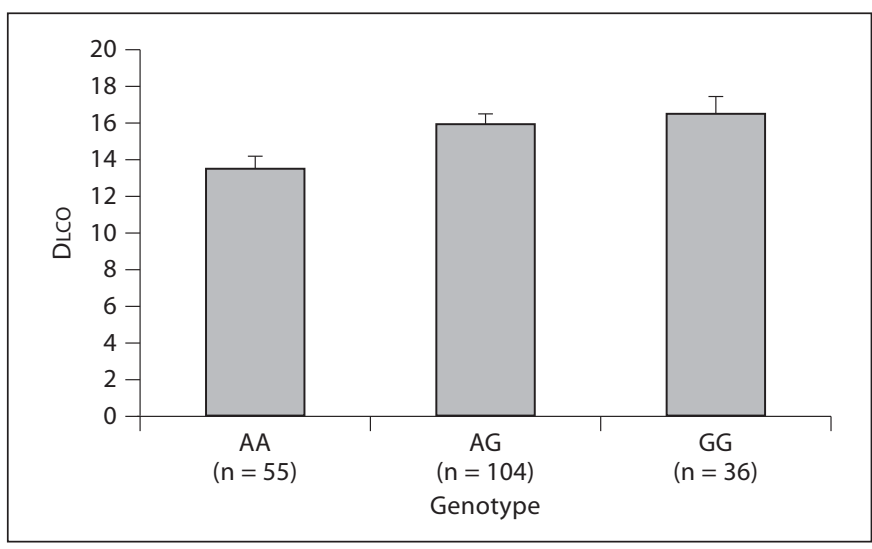

Fig. 2. DLCO by CHRNA3 genotype (rs1910984) in the KOLD cohort. Mean values ( \pm SEM) for DLCO are shown.

SNPs identified in Caucasians were not significantly associated with lung cancer risk in Chinese populations. However, commonly identified SNPs in the Chinese population, including rs12910984, were associated with lung cancer [12]. Interestingly, the A allele of rs12910984 was 
previously identified as a risk allele for lung cancer, and here we show that the A allele of rs12910984 is also a risk allele for COPD in a Korean population. Another study in a Chinese population identified common SNPs in CHRNA3, one of which showed a significant association with lung cancer risk and prognosis [18]. One report suggests a genetic association between rs1051730 and emphysema and pulmonary function [11]. In this study, SNPs were not associated with $\mathrm{FEV}_{1}$ or the emphysema index; however, they were significantly associated with DLCO. It is interesting that the risk allele of rs12910984 for COPD was associated with a lower DLCO, which may be associated with emphysema.

Interestingly, there are several genetic risk genes common to both COPD and lung cancer [19]. In the present study, rs12910984 was identified as a risk factor for COPD, showing the same trend as in a recent lung cancer study in the Chinese population. Although COPD and lung cancer can be initiated by a common environmental factor of cigarette smoking, it remains unclear whether they have a common pathogenic mechanism [20]. Our finding may reflect that CHRNA3 can be a common susceptibility gene; however, this may be due to a possible confounding effect [8]. The amount an individual smoked was significantly associated with CHRNA3/5 expression in COPD subjects in Caucasian and Asian populations [2123]. In another study, rs660652 in CHRNA3 was significantly associated with smoking dependence [24]. However, genetic variation in the CHRNA3 gene was not associated with smoking amount in the current study. The association between CHRNA3 and smoking behavior and addiction is controversial [25]. In this study, a variant of rs660652, which was associated with more lifetime smoking, showed an association with lower DLCO after adjusting for smoking amount. It is not clear whether multiple functional genes mediate different phenotypes including lung function, smoking, and emphysema [21] or share the same pathogenesis. CHRNA3 is a subunit of the nicotine cholinergic receptor. The cholinergic system is expressed not only in cholinergic neuronal cells but also in bron- chial epithelial cells [26] and airway inflammatory cells [27]. The expression of this receptor in the airways may be modified by nicotine in cigarette smoke and could potentially influence the pathogenesis of lung cancer and COPD.

There are several limitations to this study. First, there were significant differences in the demographics of the case and control subjects, as well as in the pack-years of cigarette smoking between the two groups. Specifically, like in many COPD case-control studies, age and smoking amount were higher in the study group [28]. Therefore, we adjusted for age and smoking amount in our statistical analysis. After stratification of control for smoking amount and age, we found that the results were the same. Second, the number of cohort subjects is relatively small, and our results showed only marginally significant $p$ values. We evaluated a few SNPs within a limited genetic region, so common functional variants in Korean patients may not have been tagged. However, considering that SNPs in the chromosome $15 \mathrm{q} 25$ region were associated with COPD and lung function in other populations, our results for the Asian population are likely to be meaningful. Functional data for this variant are currently lacking. However, rs12910984 is in tight linkage disequilibrium with rs6495309, which showed a significant association with lung cancer and increased CHRNA3 expression [12]. This may also have a functional effect in COPD pathogenesis. Further studies are needed to evaluate the role of CHRNA3 in COPD.

In conclusion, genetic variation in CHRNA3 is associated with COPD and DLCO in the Korean population.

\section{Acknowledgements}

This study was supported by a grant from the Korea Healthcare Technology R\&D Project, Ministry for Health and Welfare (A102065), and the Basic Research Program (2010-0021410) through the National Research Foundation of Korea (NRF) funded by the Ministry of Education, Science, and Technology, Republic of Korea.

\section{References}

\footnotetext{
Rabe KF, Hurd S, Anzueto A, Barnes PJ Buist SA, Calverley P, Fukuchi Y, Jenkins C, Rodriguez-Roisin R, van Weel C, Zielinski J: Global strategy for the diagnosis, management, and prevention of chronic obstructive pulmonary disease: GOLD executive summary. Am J Respir Crit Care Med 2007;176: 532-555.
}

\footnotetext{
2 Buist AS, McBurnie MA, Vollmer WM, Gillespie S, Burney P, Mannino DM, Menezes AMB, Sullivan SD, Lee TA, Weiss KB, Jensen RL, Marks GB, Gulsvik A, NizankowskaMogilnicka E: International variation in the prevalence of COPD (the BOLD study): a population-based prevalence study. Lancet 2007;370:741-750.
} 
3 Regalado J, Perez-Padilla R, Sansores R, Paramo Ramirez JI, Brauer M, Pare P, Vedal S: The effect of biomass burning on respiratory symptoms and lung function in rural Mexican women. Am J Respir Crit Care Med 2006;174:901-905.

$\checkmark 4$ Wan ES, Silverman EK: Genetics of COPD and emphysema. Chest 2009;136:859-866.

75 Weiss ST: What genes tell us about the pathogenesis of asthma and chronic obstructive pulmonary disease. Am J Respir Crit Care Med 181:1170-1173.

6 Hung RJ, McKay JD, Gaborieau V, Boffetta P, Hashibe M, Zaridze D, Mukeria A, Szeszenia-Dabrowska N, Lissowska J, Rudnai P, Fabianova E, Mates D, Bencko V, Foretova L, Janout V, Chen C, Goodman G, Field JK, Liloglou T, Xinarianos G, Cassidy A, McLaughlin J, Liu G, Narod S, Krokan HE, Skorpen F, Elvestad MB, Hveem K, Vatten L, Linseisen J, Clavel-Chapelon F, Vineis P, Bueno-de-Mesquita HB, Lund E, Martinez C, Bingham S, Rasmuson T, Hainaut P, Riboli E, Ahrens W, Benhamou S, Lagiou P, Trichopoulos D, Holcatova I, Merletti F, Kjaerheim K, Agudo A, Macfarlane G, Talamini R, Simonato L, Lowry R, Conway DI, Znaor A, Healy C, Zelenika D, Boland A, Delepine M, Foglio M, Lechner D, Matsuda F, Blanche H, Gut I, Heath S, Lathrop M, Brennan P: A susceptibility locus for lung cancer maps to nicotinic acetylcholine receptor subunit genes on $15 q 25$. Nature 2008; 452:633-637.

7 Amos CI, Wu X, Broderick P, Gorlov IP, Gu J, Eisen T, Dong Q, Zhang Q, Gu X, Vijayakrishnan J, Sullivan K, Matakidou A, Wang Y, Mills G, Doheny K, Tsai Y-Y, Chen WV, Shete S, Spitz MR, Houlston RS: Genomewide association scan of tag SNPs identifies a susceptibility locus for lung cancer at 15q25.1. Nat Genet 2008;40:616-622.

$>8$ Young RP, Hopkins RJ, Hay BA, Epton MJ, Black PN, Gamble GD: Lung cancer gene associated with COPD: triple whammy or possible confounding effect? Eur Respir J 2008; 32:1158-1164.

$>9$ Pillai SG, Ge D, Zhu G, Kong X, Shianna KV, Need AC, Feng S, Hersh CP, Bakke P, Gulsvik A, Ruppert A, Lødrup Carlsen KC, Roses A, Anderson W, Rennard SI, Lomas DA, Silverman EK, Goldstein DB, Investigators I: A genome-wide association study in chronic obstructive pulmonary disease: identification of two major susceptibility loci. PLoS Genet 2009;5:e1000421.

-10 DeMeo DL, Mariani T, Bhattacharya S, Srisuma S, Lange C, Litonjua A, Bueno R, Pillai SG, Lomas DA, Sparrow D, Shapiro SD, Criner GJ, Kim HP, Chen Z, Choi AMK, Reilly J, Silverman EK: Integration of genomic and genetic approaches implicates IREB2 as a COPD susceptibility gene. Am J Hum Genet 2009;85:493-502.
11 Lambrechts D, Buysschaert I, Zanen P, Coolen J, Lays N, Cuppens H, Groen HJ, Dewever W, van Klaveren RJ, Verschakelen J, Wijmenga C, Postma DS, Decramer M, Janssens W: The $15 q 24 / 25$ susceptibility variant for lung cancer and chronic obstructive pulmonary disease is associated with emphysema. Am J Respir Crit Care Med 2010;181:486493.

12 Wu C, Hu Z, Yu D, Huang L, Jin G, Liang J, Guo H, Tan W, Zhang M, Qian J, Lu D, Wu $\mathrm{T}$, Lin D, Shen H: Genetic variants on chromosome 15q25 associated with lung cancer risk in Chinese populations. Cancer Res 2009;69:5065-5072.

13 Kim WJ, Oh YM, Sung J, Lee YK, Seo JB, Kim N, Kim TH, Huh JW, Lee JH, Kim EK, Lee JH, Lee SM, Lee S, Lim SY, Shin TR, Yoon HI, Kwon SY, Lee SD: CT scanning-based phenotypes vary with $A D R B 2$ polymorphisms in chronic obstructive pulmonary disease. Respir Med 2009;103:98-103.

14 Standardization of spirometry, 1994 update. Am J Respir Crit Care Med 1995;152:11071136.

15 Cho YS, Go MJ, Kim YJ, Heo JY, Oh JH, Ban HJ, Yoon D, Lee MH, Kim DJ, Park M, Cha SH, Kim JW, Han BG, Min H, Ahn Y, Park MS, Han HR, Jang HY, Cho EY, Lee JE, Cho NH, Shin C, Park T, Park JW, Lee JK, Cardon L, Clarke G, McCarthy MI, Lee JY, Lee JK, Oh B, Kim HL: A large-scale genome-wide association study of Asian populations uncovers genetic factors influencing eight quantitative traits. Nat Genet 2009;41:527534.

16 Barrett JC, Fry B, Maller J, Daly MJ: Haploview: analysis and visualization of $\mathrm{LD}$ and haplotype maps. Bioinformatics 2005;21: 263-265.

17 Shiraishi K, Kohno T, Kunitoh H, Watanabe S, Goto K, Nishiwaki Y, Shimada Y, Hirose H, Saito I, Kuchiba A, Yamamoto S, Yokota $\mathrm{J}$ : Contribution of nicotine acetylcholine receptor polymorphisms to lung cancer risk in a smoking-independent manner in the Japanese. Carcinogenesis 2009;30:65-70.

Niu X, Chen Z, Shen S, Liu Y, Zhou D, Zhang J, Li Z, Yu Y, Liao M, Lu S, He L: Association of the CHRNA3 locus with lung cancer risk and prognosis in Chinese Han population. J Thorac Oncol 2010;5:658-666.

19 Young RP, Hopkins RJ: How the genetics of lung cancer may overlap with COPD. Respirology 2011;16:1047-1055.

20 Adcock IM, Caramori G, Barnes PJ: Chronic obstructive pulmonary disease and lung cancer: new molecular insights. Respiration 2011;81:265-284.

21 Pillai SG, Kong X, Edwards LD, Cho MH, Anderson WH, Coxson HO, Lomas DA, Silverman EK: Loci identified by genome-wide association studies influence different disease-related phenotypes in chronic obstructive pulmonary disease. Am J Respir Crit Care Med 2010;182:1498-1505
22 Siedlinski M, Cho MH, Bakke P, et al: Genome-wide association study of smoking behaviours in patients with COPD. Thorax 2011;66:894-902.

23 Li MD, Yoon D, Lee JY, Han BG, Niu T, Payne TJ, Ma JZ, Park T: Associations of variants in CHRNA5/A3/B4 gene cluster with smoking behaviors in a Korean population. PLoS One 2010;5:e12183.

24 Erlich P, Hoffman S, Rukstalis M, Han J, Chu X, Linda Kao W, Gerhard G, Stewart W, Boscarino J: Nicotinic acetylcholine receptor genes on chromosome $15 \mathrm{q} 25.1$ are associated with nicotine and opioid dependence severity. Hum Genet 2010;128:491-499.

25 Liu JZ, Tozzi F, Waterworth DM, Pillai SG, Muglia P, Middleton L, Berrettini W, Knouff CW, Yuan X, Waeber G, Vollenweider P, Preisig M, Wareham NJ, Zhao JH, Loos RJ, Barroso I, Khaw KT, Grundy S, Barter P, Mahley $\mathrm{R}$, Kesaniemi A, McPherson R, Vincent JB, Strauss J, Kennedy JL, Farmer A, McGuffin P, Day R, Matthews K, Bakke P, Gulsvik A, Lucae S, Ising M, Brueckl T, Horstmann S, Wichmann HE, Rawal R, Dahmen N, Lamina C, Polasek O, Zgaga L, Huffman J, Campbell S, Kooner J, Chambers JC, Burnett MS Devaney JM, Pichard AD, Kent KM, Satler L, Lindsay JM, Waksman R, Epstein S, Wilson JF, Wild SH, Campbell H, Vitart V, Reilly MP, Li M, Qu L, Wilensky R, Matthai W, Hakonarson HH, Rader DJ, Franke A, Wittig M, Schafer A, Uda M, Terracciano A, Xiao X, Busonero F, Scheet P, Schlessinger D, St Clair D, Rujescu D, Abecasis GR, Grabe HJ, Teumer A, Volzke H, Petersmann A, John U, Rudan I, Hayward C, Wright AF, Kolcic I, Wright BJ, Thompson JR, Balmforth AJ, Hall AS, Samani NJ, Anderson CA, Ahmad T, Mathew CG, Parkes M, Satsangi J, Caulfield M, Munroe PB, Farrall M, Dominiczak A, Worthington J, Thomson W, Eyre S, Barton A, Mooser V, Francks C, Marchini J: Metaanalysis and imputation refines the association of $15 \mathrm{q} 25$ with smoking quantity. Nat Genet 2010;42:436-440.

26 Minna JD: Nicotine exposure and bronchial epithelial cell nicotinic acetylcholine receptor expression in the pathogenesis of lung cancer. J Clin Invest 2003;111:31-33.

27 Gwilt CR, Donnelly LE, Rogers DF: The nonneuronal cholinergic system in the airways: an unappreciated regulatory role in pulmonary inflammation? Pharmacol Ther 2007; 115:208-222.

28 Castaldi PJ, Cho MH, Cohn M, Langerman F, Moran S, Tarragona N, Moukhachen H, Venugopal R, Hasimja D, Kao E, Wallace B, Hersh CP, Bagade S, Bertram L, Silverman EK, Trikalinos TA: The COPD genetic association compendium: a comprehensive online database of COPD genetic associations. Hum Mol Genet 2010;19:526-534. 